\title{
Open-Ocean Deep Convection Explored in the Mediterranean
}

\author{
The THETIS Group
}

Open-ocean deep convection is a little. understood process occurring in winter in remote areas under hostile observation conditions, for example, in the Labrador and Greenland Seas and near the Antarctic continent. Deep convection is a crucial link in the "Great Ocean Conveyor Belt" |Broecker. 1991], transforming poleward flowing warm surface waters through atmosphere-ocean interaction into cold equatorward flowing water masses. Understanding its physics, interannual variations, and role in the global thermohaline circulation is an important objective of climate change research.

In convection regions, drastic changes in water mass properties and distribution occur on scales of 10-100 km. These changes $O c$ cur quickly and are difficult to observe with conventional oceanographic techniques. Apart from observing the development of the decp minxed pratch of homogencous water itself, processes of interest are convective plumes on scales $<1 \mathrm{~km}$ and vertical veloci. ties of several cm s' [Schott et al., 1994] that quickly mix water masses vertically, and instability processes at the rim of the convection region that expedite horizontal ex. changes of corivected and background water masses [e. s., Guscard, 1978].

Ocean acoustic tomography may help measure the three-dimensional development of convection regimes. Two acoustic tomog. raphy experiments were recently carried out in the Greenland Sea [Worcester et al., 1993] and in the northwestern Mediterranean.

The second, named the Theoretical and Experimental Tomography in the Sea Experiment (THETIS), was carried out from November 1991 to April 1992 in cooperation with groups from several European laboratories. Ocean acoustic tomography was applied in conjunction with conventional and advanced physical oceanography observations to measure the effects of deep convection on the water mass distribution and resulting circulation in the Gulf of Lions (Figure la).

The northern Mediterranean current, flowing westward along the southern coast of France and recirculating partially eastward north of the Baleares, causes uplift of the density surfaces in the center of this cy. clonic circulation cell.
The vertical stratification is three-layered: the surface-mixed layer is separated from weakly stratified deep waters by a warmer and saltier intermediate layer at $150-500 \mathrm{~m}$, the Levantine Intermediate Water (LIW). which originates in the eastern Mediterra. nean basin. When cold and dry offshore winds, called "Mistral," blow over this area, the center of the dome where the surfacemixed layer is thinnest is the region where deep convection is most likely to begin.

The deep-mixed region is centered near $42^{\circ} \mathrm{N}, 5^{\circ} \mathrm{E}$ and can change size and shape within weeks. The maximum extent as observed in 1969 [Medoc Group, 1970] and 1987 [Leaman and Scholt, 1991] (referred to as $L S 91$ and SLOI in the following) are shown in Figure la. A meridional density section through the region along $5^{\circ} \mathrm{E}$ (Figure Ib) shows the preconditioning dome in November 1991 and the homogenization by deep convection in late February 1992.

The field experiment (Figure la) con. sisted of a tomography array of six transceiv. ers for observing the large-scate evolution, covering the possible extent of the deepmixed patch; a small-scale mooring array within the center of the patch to observe onset and the detailed three-dimensional evolu tion of the convection activity and plumes; a boundary array across the northern current to measure the cyclonic circulation and pos. sible variations related to convection; and ship surveys during different phases of the winter period.

The small-scale array continuously monitored the vertical stratification over the depth range where convection might occur. Hence one station (Al, Figure la) was equipped with two thermistor strings and conductivity/ salinity recorders at several depths.

Each station of the small-scale array carried downward looking acoustic Doppler current profilers (ADCPs) at 320-m depth with a range of about $300 \mathrm{~m}$. Station Al was also equipped with an upward looking $A D C P$ to measure velocities in the mixed layer. This ADCP also allowed measurements of surface backscatter, leading to information on local winds.

Ship surveys were carried out immediately after deployment, to document stratif- cation and circulation during the precondi. tioning phase, when pronounced doming of the isopycnals usually occurs. Another ship survey followed in late February, when the main phase of convection was expected. Grid surveys and small-scale conductivity. temperature-depth (CTD) work was done to investigate the plume scale of convection events. In April, during the retrieval cruise, a last ship survey was carried out to investigate the final water mass and convection status. Freons were measured on two of the cruises to delineate convected water masses from the environment.

The tomographic transceivers used in the experiment had a range of about $300 \mathrm{~km}$ and were deployed at $150-\mathrm{m}$ depth, which allowed sampling of the surface, the LWW, and the deep layer. A technical failure of several transceivers led to successive malfunction of the tomographic system during the precondt tioning phase. Instrument pair T3-T6 continued into early February, allet which all sta tions (except T4) were retrieved and repaired.

The network was back in operation at the end of February, following the main convection phase. Hence comparisons of tomo. graphic inversions with oceanographic verifi cation data are most complete for the first phase of the experiment and from the rede ployment of the repaired stations until the end of the experiment. Because the time se.ies of station pair T3 T6 covered almost the entire recording period, they were used to compare methods and verify the oceanographic "ground truth" data.

\section{Hedt Fluxes and Convection}

Apart from the gradual seasonal cooling. several events of strong negative surface hea flux occurred in the Gulf of Lions during the winter of 1991/1992. Each event had a clear signature in the oceanographic processes observed. The events are seen in the air-sea heat fluxes over the region (Figure $2 a$ ) taken from the French Peridot weather model and were associated with strong winds and cold and/or dry air.

The first strong wind period of the sea. son occurred in late December. At night 
time, air temperature minima combined with high wind speeds, causing large sensible and latent heat loss, totaling about $500 \mathrm{~W} / \mathrm{m}^{2}$ in the model time series. After December, some intermediate cooling occurred in late January and early February.

In mid-February, there was a Mistral event with coastal night temperature minima near $3^{\circ} \mathrm{C}$; the Peridot model during this episode shows two $500 \mathrm{~W} / \mathrm{m}^{2}$ heat loss maxima and our shipboard observations confirm these values. By then, the stratification had eroded so that the strong cooling could break through the mixed layer and generate deep convection. This was the main convection event.

The mean heat fluxes then gradually returned to positive values with increasing solar radiation, interrupted by two other cooling periods in late March and mid-April. The last cooling episode with fluxes of up to 600 $\mathrm{W} / \mathrm{m}_{2}$ heat loss occurred from April 20 to 24 . but was not able to break through the al- . ready restratified water column.
The strong cooling events have an immediate effect on the vertical velocity either as mixing/internal wave signals or due to the deep convective motions. This is visible in the time series of vertical velocity at the Al mooring. Figure $2 \mathrm{a}$ includes the variance of this quantity and activity during the heat flux events is visible.

Detailed analyses show that the energy maximum in December results from internal wave variability in the stratified layer, while the maximum during the deep convection phase in February is due to vertically coherent cells of downward flow with weaker up. ward motions in between.

Figures $2 b$ and $2 c$ show the evolution of temperature stratification in the region with individual time series from the central mooring $\mathrm{Al}$ (Figure $2 \mathrm{~b}$ ) and as a contour plot of the average from temperature sensors on moorings $\mathrm{A} 1$ and $\mathrm{T} 3$ in the south (Figure 2c). The subsurface temperature maximum at $150-500 \mathrm{~m}$ depth represents the warm, salty LIW layer. The initial cooling and wind mixing during December begins to erode the warm surface layer.

During January the upper-layer temperature decreases further until through the combined effects of density increase and wind mixing warmer LIW water is entrained upward. This results in a phase of surface-temperature increase despite the ongoing cooling. Then, after the vigorous Mistral cooling period of mid-February the temperature records show homogenized water down to below $1000 \mathrm{~m}$, indicating that deep convection has occurred.

The cruise in mid-February surveyed the extent of the mixed patch. Judging from increased surface salinity values mapped with an underway thermosalinograph, the mixed region reached from $42^{\circ} 35^{\prime} \mathrm{N}$ to just south of the $A D C P$ array (Figure la).

CTD casts revealed that convection only reached depths of about $1600 \mathrm{~m}$ in February 1992 ; in 1987, it had extended to more than $2000 \mathrm{~m}$. Further, as shown by the CTD-Toyo

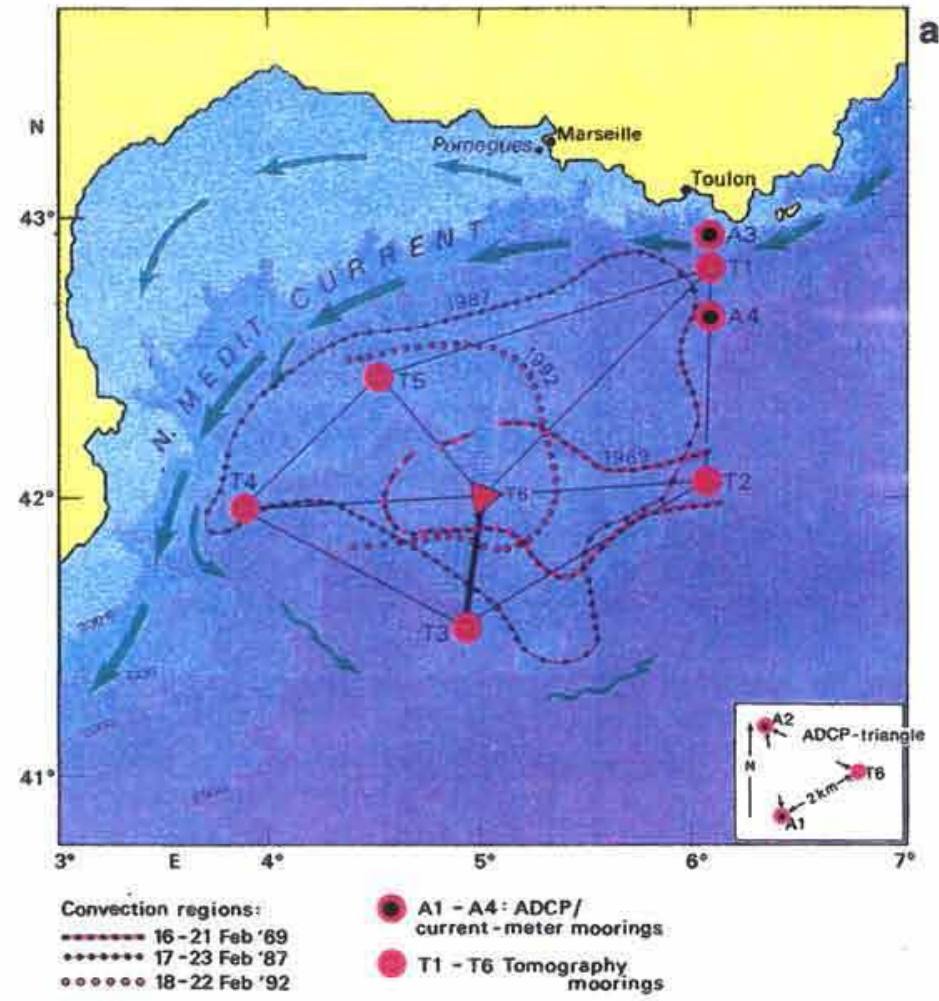

Fig. 1 . a) Circulation schematics, extent of deep-mixed regimes in different years and THETIS array 1991/1992. Inset shows orientation of small-scale acoustic Doppler current profiler triangle deployed near $42^{\circ} \mathrm{N}, 5^{\circ} \mathrm{E}$. b) Section of potential density, sigma-theta, along $50^{\circ} \mathrm{E}$ during the preconditioning phase (November 27-28, 1991) showing the "doming" (top) and homogenization after deep convection (February 20-22, 1992, bottom).
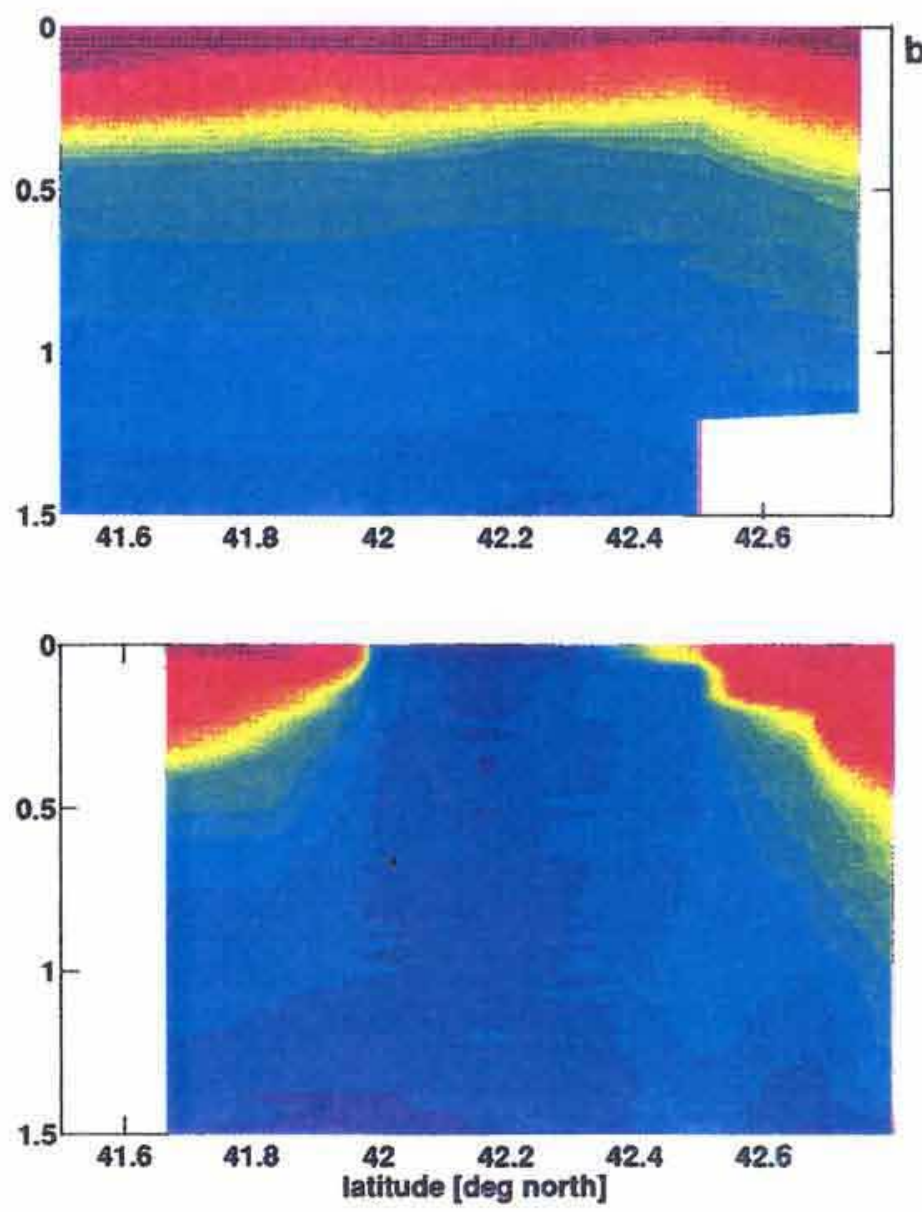

sigma theta $\left[\mathrm{kg} / \mathrm{m}^{\wedge} 3\right]^{29.05}$




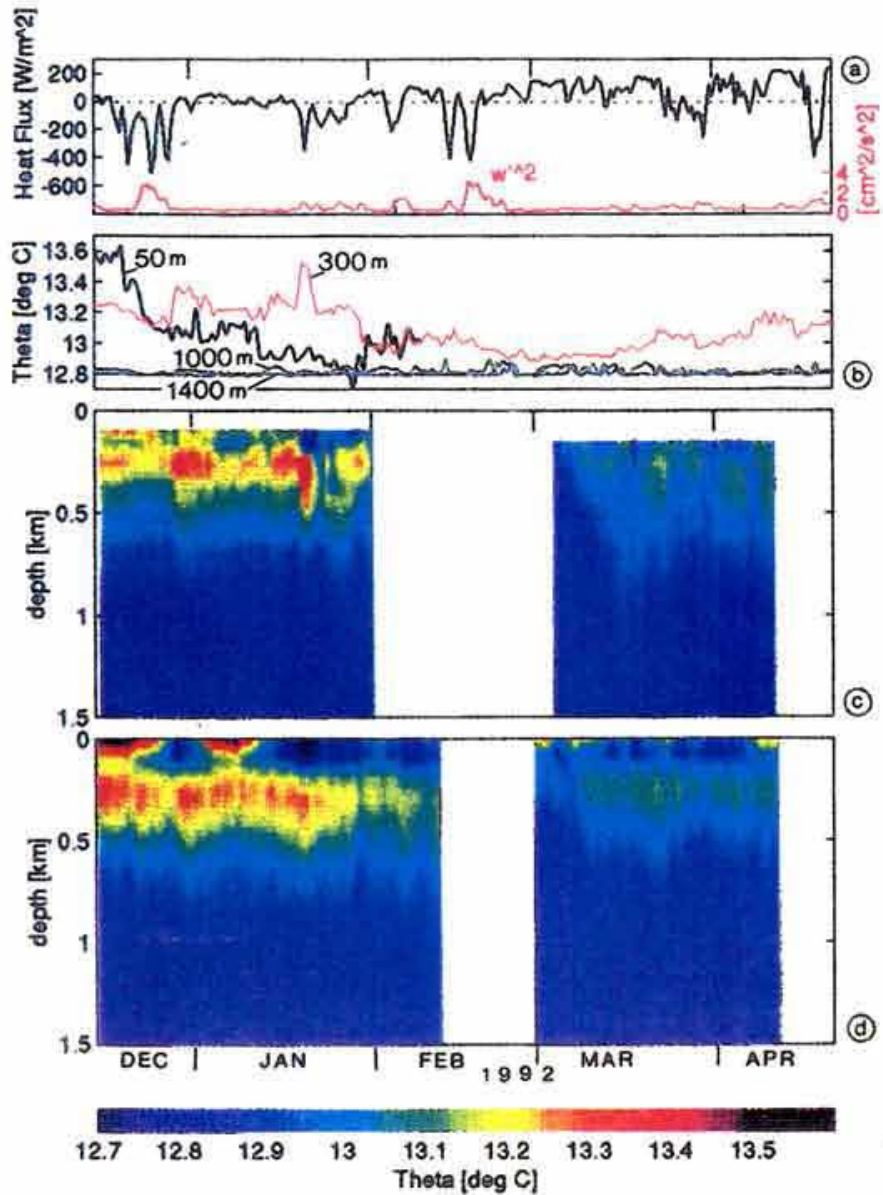

Fig. 2. Time series of various quantities from convection region during winter 1991/1992. a) Net heat flux over convection region from Peridot model at $42^{\circ} \mathrm{N}, 5^{\circ} \mathrm{E}$ and vertical velocity variance from central mooring (AI) at 140-m depth; b) time series of individual temperature sensors on mooring Al; c) depth-time contour plot of mooring temperature time series, averaged from positions $A l$ and $T 3$; d) Tomography inversion for average temperature between $T 6(\mathrm{Al})$ and T3, same presentation and color codes as in part $c$.

sections, the 1992 convection was a case of "incomplete mixing," because significant three-dimensional differences in water mass properties remained within the mixed regime. Hence the convection region estimated by the surface salinity boundary in Figure la is characterized by lack of the LIW layer intermediate maxima in temperature and salinity rather than by complete homogeneity.

Two weeks after the convection, CTD profiles showed complicated vertical and horizontal patterns, indicating horizontal exchange of convected and stratified water. Acoustic transmissions averaged over these and the above small-scale inhomogeneities, yielding the range-average temperatures.

Thus tomography provides smoother views of the large-scale fields and helps estimate the volume of convected water.

\section{Tomographic Inversion Results}

The data used in the tomography inversions were travel times of acoustic arrival peaks. They were first corrected for mooring motion based on acoustic navigation of the tomography moorings using bottom transponders. The arrivals represent individual ray paths through different parts of the water column and could be identified based on initial or historical hydrographic background information. The acoustic arrival peaks were tracked by a newly developed automatic rou- tine and time series of travel time anomalies were determined.

The travel time anomalies along the ray paths were then inverted to yield the amplitudes of vertical sound speed anomaly empirical orthogonal functions (EOFs). The EOF patterns were based on all CTD data collected during the five cruises.

With three to five of the EOFs the changes between the preconditioning stratifcation, characterized by the intermediate UW temperature maximum (Figure 2c), and the various degrees of homogenization could be well described. Thus the tomography data yielded time series of the vertical temperature distribution averaged between mooring pairs.

Though there are many tests for checking tomography results obtained with other oceanographic data, they have limitations since tomography provides a different view of the ocean than conventional oceanographic measurements. A qualitative comparison is shown in Figure $2 \mathrm{~d}$ for the inversion of station pair T3-T6, where color contour plots are presented using the same color scale and axes as for the mooring temperatures from stations T3 and T6. The moorings have less complete vertical coverage since they do not extend to the surface. Therefore much of the surface layer evolution is lost. In this environment, however, the tomography can sample the near-surface layer.
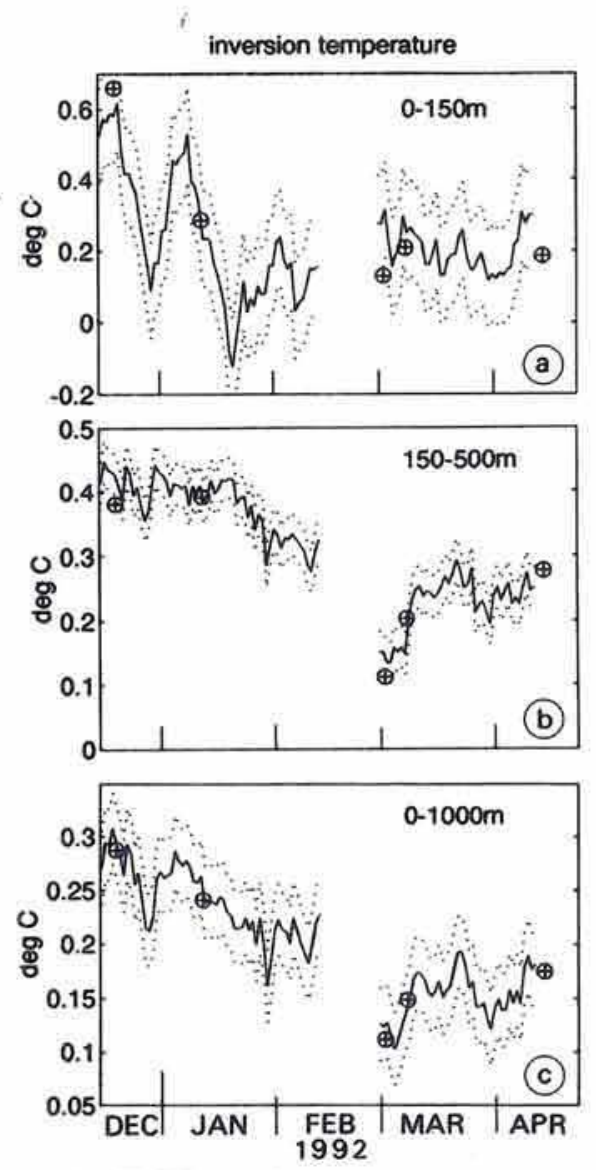

Fig. 3. T3-T6 inversion temperature averages (relative $12.78^{\circ} \mathrm{C}$ ) for layers $a, 0-150 \mathrm{~m}$; b, 150-500 m; and c, 0-1000 m, compared with conductivity-temperature-depth station estimates, when at least two CTD stations were along the section.

The time series of the acoustic inversions may be compared with hydrographic observations by forming vertical averages of various layers of interest. This has been done for the surface layer $(0-150 \mathrm{~m})$, the LIW layer $(150-500 \mathrm{~m})$, and the deepest layer sampled with the refracted rays (Ole water column.

Figure 3 shows the temperature time series from tomography for these layers. The agreement between tomography and CTD data in Figure 3 is good and always within the error bars of the inversion. This is reasonabile confirmation that the tomography yielded reliable data.

\section{Future Plans}

A new project, THETIS-2, is applying acoustic tomography across the entire westem Mediterranean from January through October 1994. The center of this experiment is a more powerful sound source with about $1000-\mathrm{km}$ range. The project will measure seasonal stratification and heat storage changes and estimates of the skill at determining three-dimensional basin averages. Eventually, interior basin measurements will be tied together with inflow/outflow observa- 
EOS, TRANSACTIONS, AMERICAN GEOPHYSICAL UNION

tions and surface heat fluxes.

Future plans of investigators cooperating with THETIS focus on studying deep water production and redistribution in the western subpolar Atlantic on an interannual basis. Here the methods demonstrated in the Mediterranean convection regime can be applied to one of the important source areas of conveyor belt variability.

\section{Acknowledgments}

THETIS and THETIS- 2 are funded by the Marine Science and Technology (MAST) Program of the European Communities (EC), DG XII under contracts MAST-0008-C and MAS2CT91-0006. Buildup of the technical capability for ocean acoustic tomography at the Institut für Meereskunde, Kiel, Germany, was made possible by the German Minister of
Science and Technology under contract 03F0542A.

\section{The THETIS Group}

F. Schott (Principle Investigator), U. Send, G. Krah mann, C. Mertens, and $M$. Rhein, Institut für Meereskunde, Kiel, Germany; M. Visbeck. Institut für Meereskunde, Kiel, Germany, presently at Massachusetts Institute of Technology. Cambridge; $Y$. Desaubies, F. Gaillard, and T. Terre, IFREMER, Plouzané, France; M. Taroudakis, Institute for Applied Computational Mathematics, FORTH and Un versity of Crete, Heraklion. Greece; G. Athanassoulis and E. Skarsoulis, Institute for Applied Computational Mathematics, FORTH and University of Crete, Heraklion, Greece, and National Techni. $\mathrm{cal}$ University of Athens, Greece

\section{References}

Broecker, W. S., The great ocean conveyor, Ocean ography, 4, 79, 1991.

Gascard, J.C. Mediterranean deep water formation baroclinic instability and oceanic eddies. Oceanol. Acta, I, 315, 1978

Leaman, K. D., and F. Schort, Hydrographic struc ture of the convection regime in the Golfe du Lion, J. Phys. Oceanagr, 21, 575, 1991.

MEDOC Group, Observation of formation of deep water in the Mediterranean Sea, 1969, Nature. 227, $1037,1970$.

Schott, F., M. Visbeck, and U. Send, Open ocean deep convection. Mediterranean and Greenland Seas, in Ocean Processes in Climate Dynamics. edited by P. Malanotte-Rizzoli and A. Robinson, Kluwer, pp. 203-225, 1993.

Worcester, P. F., et al., Evolution of the large-scale temperature field in the Greenland Sea dunng 1988-89 from tomographic measurements, Geo phys. Res. Lett., 20, 2211, 1993. 